\title{
EMPLOYEE RETICENCE: DEVELOPMENT AND VALIDATION OF ITS SCALE
}

\author{
Ahmed Ali Qureshi ${ }^{1 *}$, Sayyed M. Mehdi Raza Naqvi ${ }^{2}$ \\ ${ }^{1 *, 2}$ Capital University of Science and Technology, (CUST), Islamabad, Pakistan. \\ Email: ${ }^{1 *}$ qureshi.ahmadali@gmail.com, ${ }^{2}$ razanaqvi@cust.edu.pk
}

Article History: Received on $12^{\text {th }}$ April 2021, Revised on $23^{\text {rd }}$ April 2021, Published on $27^{\text {th }}$ April 2021

\begin{abstract}
Purpose of the study: The purpose of the study was twofold, first to find the antecedents and consequences of employee voice using the theory of planned behaviour, and second to develop, introduce and validate the construct of employee reticence (employee-silence attitude) and its scale.
\end{abstract}

Methodology: Mixed-Method Research using interviews, and questionnaire was the methodology of the study. IBM SPSS 20.0 and SmartPLS 2.0 software were used for data analysis to test and confirm face validity, content validity, reliability, item reliability, convergent validity, discriminant validity, nomological validity.

Main Findings: Employee reticence is a valid employee attitude. The employee silence behaviour is supported by the theory of planned behaviour. It was found that the Theory of planned behaviour applies to the situations of employee silence. The scale of employee reticence developed, as the result of this study, is valid and ready to be used by researchers, organizational behaviourists, psychologists, and HR experts.

Applications of this study: The study is applicable for change intervention programs in organizations by organizational behaviourists. The researchers can use it to explore and develop organizational and team-level attitudes of silence. Its scale is a useful tool, largely for recruiters for ensuring PO fit. It is usable to researchers for further exploration and using it as in organizational research including but not limited to Employee silence, knowledge management, and stress. Psychologists can take the lead from the concept of ER to develop similar constructs for their field for analysing their patients of stress etc. from this perspective.

Novelty/Originality of this study: The study is novel and original as the construct of employee reticence has been developed, introduced, and validated (employee-silence attitude). Further, the scale of the new construction has been constructed and validated, using standard methods.

Keywords: Attitude, Employee Reticence, Employee Silence, Scale Development, Scale Validation.

\section{INTRODUCTION}

Employee silence is the intentional withholding of suggestion(s) intended for workplace improvement (Benevene, 2020; Morrison, 2014), it is a pervasive and internationally occurring phenomenon (Götz et al., 2019) across sexualities (Priola et al., 2014). The previous researchers have explored the dispositional and organizational level antecedents of employee silence (ES); however, they ignored a very vital aspect at the employee level that contributes towards the formation of silence behavior. This research has tried to capture this missing link of employee's attitudes towards silent behavior, which is a novelty and strong contribution to the existing body of knowledge.

One of the reasons why ES attitude has not been discussed in the previous literature is due to the lack of such a construct and unavailability of the scale to measure it. Thus, the main objective of the study is to define and to operationalize it. Secondly, its objective is to develop, validate and test its scale developed as the result of this study. Further, the rationale of addressing this gap derives from the theory of planned behaviour (TPB) (Ajzen, 1985) which postulates that attitude formulates intentions that contribute towards behavioral depictions.

The current research has identified and explored a very interesting variable, employee reticence, as an important antecedent of ES especially in the service sector, where competitive edge depends on employee's behavior.

Employee-attitude-towards-silence referred to as Employee Reticence (ER) is being proposed in this research as an attitude that pertains to the favorable evaluation of silent behavior at the workplace. According to the Oxford Dictionary, the word "reticence" originated in the mid-19th-century in Rome referred to as "remaining silent" and in English, it means "not revealing one's thoughts or feelings readily". Taking lead from this research we have used ER as favorable feelings and beliefs of an employee towards silent behavior in the organization. In literature silence behavior in an organization is referred to as ES (Knoll \& van Dick, 2013) which is an omnipresent phenomenon in modern organizations (Lam \& Xu, 2019) and dangerous for organizations (Abd El-Fattah Mohamed Aly et al., 2021). Its antecedents include factors at the individual level, group level, and organizational level (Knoll \& Redman, 2016; Morrison, 2011; Tangirala \& Ramanujam, 2012). However, the review of extant literature suggests that the individual level factor that is employee attitude towards silence has not to be investigated as an antecedent of ES. The significance of this research is embedded in introducing the concept of ER.

The significance of this research has multiple dimensions. First, the research makes a significant theoretical contribution by proposing a new variable titled ER. Secondly, the scale of ER has been developed, validated and tested using 
qualitative and quantitative approaches. Finally, the findings of this research are useful for academicians to further explore ER, its antecedents, and consequences and further update the concept of ER.

The main objective of the study is to define and operationalize employee reticence. Secondly, its objective is to develop, validate and test, through hypotheses testing, its scale developed as the result of this study. For the sake of testing the developed scale, there were three objectives of the study, which are:

1) To find out if employee reticence is positively related to employee intentions to remain silent, and

2) To find out if intentions to remain silent is positively related to employee silence, and

3) If intentions to remain silent mediates the relationship between employee reticence and employee silence.

\section{LITERATURE REVIEW}

\section{Employee Reticence}

Proposing the new job attitude warrants a brief discussion on attitudes. Extant literature exists on describing and understanding attitudes. The earlier researchers have described bi-polar evaluative-ness as an essential characteristic of attitude(Ajzen \& Fishbein, 2005; Eagly \& Chaiken, 1993; Fazio, 1990), however, a few researchers have defined it as the evaluative response itself (Kruglanski \& Stroebe, 2005), while most contemporary researchers equate attitude with the hypothetical disposition (Eagly \& Chaiken, 2005) and have concluded that attitudes can be inferred from evaluative responses towards the subject, object or behavior. In this research, the contemporary school of thought on attitudes has been adopted. That is evaluative responses towards job-related behaviors such as ES has been used to infer job-related attitudes such as ER. It is proposed in this research as a new job attitude. It has been defined as "Favorable feelings and beliefs of an employee towards silence behavior in organizations" based on the definition of attitudes by Eagly and Chaiken (2005).

In wholesome ER has been operationalised as favorable feelings and beliefs of an employee towards silence behavior of employees in the organization. An employee, who evaluates ES as positive behavior, will score high on ER scale and vice versa. Such employees not only prefer to remain silent but also advocate and encourage other colleagues to do so. Imagine a situation where a top-level manager inquiry about a process improvement initiative. Few employees will appreciate the initiative. Few others will not have anything to say about the initiative. There will still be employees who have suggestions for the improvement initiative but will prefer to remain silent. They will themselves remain silent and will also appreciate other employees who have similar attitudes (Byrne, 1961; Orpen, 1984) and consequently will remain silent. Meaning thereby that these employees evaluate ES behavior as positive and good. These employees will have high scores on ER scale. Therefore, they are likely to perform the same behavior in future interactions (Armitage \& Christian, 2003).

ER and ES are different constructs. Employee reticence is an attitude while the construct of ES is a behavior that represents the intentional silence exhibited by employees. The relationship between ER and ES is proportional. However, this relationship is mediated by relevant intentions as proposed by TPB. It suggests that attitude contributes towards intentions which lead towards the exhibition of the behavior. Therefore, high ER would lead to intentions to remain silent which would lead to the manifestation of ES as given in Figure 1.

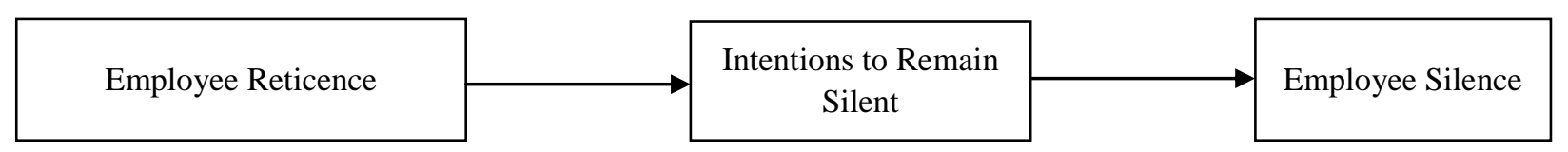

Figure 1: Theoretical framework adapted from Theory of Planned Behavior (Ajzen, 1985)

The relationship between attitudes and intentions is also supported by empirical evidence. For example, significant relationships have been found between respective attitudes and turnover-intentions such as in the study of Valentine et al., (2011) a significant relationship was found between respective attitudes and turnover intentions. The TPB also supports this assertion. According to TPB one's positive attitude towards a behavior leads to the formation of one's intentions to perform the behavior.

Therefore, getting support from the extant literature and TPB we hypothesize that ER would have a positive effect on intentions to remain silent. This argument leads to the formulation of the first hypothesis of the research as follows

\section{H1: Employee Reticence is positively related to Intention to Remain Silent.}

\section{Employee Intentions to Remain Silent and Employee Silence}

Employee silence is an intentional behavior. It is not just a mere absence of voice. It does not occur when an employee has nothing to say or is mindless (Dyne et al., 2003). ES is exhibited when an employee intentionally withholds suggestion-for-improvement from a person perceived to be capable of implementing the improvement suggestion. It is withholding ideas/suggestions intentionally due to specific reasons (Dyne et al., 2003; Knoll \& van Dick, 2013) which is also supported by the multiple intentional behavioral theories. 
The previous researchers have studied intentions as predictors of a wide array of behaviors and found a significant relationship between intentions and the exhibition of the behaviors (Howard et al., 2017). Based on the arguments, and further conceptualization the second hypothesis of this research is proposed as below:

\section{H2: Intentions to Remain Silent is positively related with Employee Silence.}

Supported by the extant literature and the TPB intentions have been found to mediate the relationship between attitudes and behavior (e.g. see (Ajzen, 1985; Chen et al., 2011; Shukla et al., 2013). Therefore, based on the TPB and empirical research the following hypothesis is proposed.

\section{H3: Intentions to Remain Silent fully mediates the relationship between Employee Reticence and Employee Silence.}

Before testing the hypotheses of the research, we developed the scale of ER. The methodology and procedure of scale development are explained below.

\section{METHODOLOGY}

In this research, we have developed the scale of ER by combining deductive and inductive approaches, as this is the best practise for the development of scale (Boateng et al., 2018). Moreover, following the contemporary school of attitudes and boundary conditions, the initial pool of items was generated.

In this research, we have used the qualitative method for a better understanding of ER and the generation of the initial items pool. The qualitative study was followed by quantitative analysis for item reduction, validity \& reliability analysis, factor analysis, and testing the research model in light of the TPB.

\section{Qualitative Study Phase}

We conducted semi-structured, in-depth interviews with 41 employees and practitioners volunteering for the study from the service sector. This step was followed by the coding analysis of the interview transcripts. As a result, the items were generated in light of the contemporary school of attitudes. Though not the part of the objectives of the study, the structural dimensions of ER was also discovered.

\section{Interview process}

The interviews were conducted with the 67 employees of the service sector. It also helped in the generation of items. Sixty-seven employees voluntarily participated in the interviews, which were from telecom, hospital, education, oil \& gas, and the courier sector. Demographic data of the interviews revealed $31.7 \%$ were the female participants. $68.2 \%$ of the participants were having 2-7 years of experience, while 17\% of the employees were having 8-13 years of experience while the rest of the employees were having experience greater than 13 .

Semi-structured and in-depth interviews were conducted during the interview phase. The interviews were conducted by experts who had in-depth knowledge of the phenomenon. Before the start of the interview, the participants were briefed about the purpose of the research. Two interviewers conducted each interview which was divided into groups of 5 each; the interview sessions lasted for approximately 1 hour. They remained very specific in explaining the meaning of attitudes / ER to have responses based on their cognitive, affective, and behavioral state of mind about ES. The interviews continued for two intervals. Each interval spanned over seven days. In the first interval, the interviews were summarized and relevant analyses were performed simultaneously. In the second interval, similar questions were asked. However, it was found that no new theme or ideas emerged. Therefore, it was concluded that increasing the sample size of the respondents would not affect the emergence of new ideas. Further, the three dimensions of ER were discovered in the first interval. Therefore, it was assumed not to take the interview phase in the third interval.

\section{Coding process}

Each interview interval was followed by the coding process. It was a two-stage process that involved (i) formal coding, and (ii) checking coding consistency. As recommended by Charmaz (2006) the interview content was grouped into firstorder code and second-order code. The coding process was performed independently by the two researchers; however, the same steps of the coding process were followed. It was cautiously done to check the coding consistency in the coding process.

During the open coding phase of the coding process, the distinct phenomena that emerged were conceptualized. As the result of the qualitative study three factors of ER were found, 1) cognitive employee reticence, 2) affective employee reticence, and 3) behavioral employee reticence. Some representative quotes from the interviews are given in Table 1.

Table 1: Some representative quotes from interviewees for item generation for Employee Reticence

\begin{tabular}{ll}
\hline Dimensions Items & Representative quotes \\
$\begin{array}{l}\text { I like the people who prefer to In organizations, it is useless to raise voices and I find such people } \\
\text { remain silent over raising } \\
\text { concerns. }\end{array}$ & $\begin{array}{l}\text { In my organization, my colleagues have gone wiser over time; they } \\
\text { stay calm and cool and let the manager take care of his bad decisions. }\end{array}$ \\
\hline
\end{tabular}


I do not like the colleagues who instead of focusing on their own

It irritates me whenever an $\mathrm{I}$ find it a total waste of time, whenever employees try to be employee gives suggestions for ingenious for the problems of other departments.

other departments.

I am amused by the colleagues whose own department is a mess and yet find suggestions for other departments.

Disagreements should only be done, when you expect something good out of it. In my experience, disagreement is a waste of time and

In organizations, disagreements in the end, the boss wins in any case.

should be avoided. Discussions are useless. In my organization, our new colleagues have to agree to all the disagreements, until the time they do disagree no more.

In this job and in the previous jobs that I have done, it's better to hold suggestions and remain silent than staking your self-respect.

In organizations, it is better to I have always been told by my seniors to hold suggestions and keep a stay quiet than to give low profile for smooth functioning in the organization.

Cognitive suggestions. My manager does whatever he has to do even when the majority of us is not in favor, so it's better to be quiet than to waste time in thinking and giving suggestions.

Conflicts in an organization can My advice to conflict management is to remain silent. There is no use be handled by remaining silent. of saying anything, it is likely to aggravate the conflict.

What I have learned from my working experience is that, people who are silent in organizations are the one giving the most to the

Remaining silent in organization by supporting the current system. Above all, barking organizations is beneficial. dogs seldom bite.

People who are focused, get their work done, without making noise. Making noise of what you are doing is useless, since what you are doing is what you are paid for, and making noise is useless.

The job assignment which may If I know there will be discussions and possible conflict, I prefer to lead to a conflict is delayed by me to the last hour. delay the task until it becomes a necessity.

I don't know, but for smooth functioning, I delay the work leading to conflicts as late as possible.

I wait for others to raise

concerns about a common I am lucky that most of the times problems similar to mine are put by

Behavioral problem rather than raising it others. I wait and like it this way.

by myself.

I have lost my hair, as I am good at absorbing pressures, so much so

I often do the undone work of that I do the task of others instead of asking them to do their task.

another employee without My colleagues often choose me as their team member as I am

raising my voice. $\quad$ reliable and mainly because they know I will go the extra mile to get the teamwork done without making noise.

\section{Findings}

Through semi-structured in-depth interviews, we found that employee reticence is three dimensional: affective, cognitive, and behavioral. Therefore, the ER concept is three-dimensional and encompasses affective, cognitive, and behavioral components. Since the dimensions were not part of the scope of the research, the qualitative analysis revealed three dimensions of ER and needs to be treated separately in future research. It has been left to the research to follow as part of future recommendations.

\section{Item generation}

The second phase of the qualitative study involved the item generation process. In this phase items developed were combined and an initial pool of 29 items to measure ER was generated. A few of the representative quotes from the qualitative interview phase are listed in Table 1. The generated pool of initial items also contained adapted items from existing scales, such from the scale of sportsmanship dimension of organizational citizenship behavior (1 item; Organ, 1988), Social Reticence Scale (two items; Jones \& Russell, 1982).

\section{Quantitative Study Phase}

In order to empirically test the theoretical model, see Figure 1, we did two studies in the quantitative study phase. In the first study, the item reduction was performed using principal component analysis as given below. 


\section{Item reduction (principal components analysis)}

The initial pool of 29 generated items was distributed among the 300 employees of the service sector. The response rate of the valid questionnaire was $72 \%$. The items were based on a Likert scale (five points) with $5=$ strongly agree and $1=$ strongly disagree. The demographics of the respondents revealed that $40.2 \%$ of them were female.

Five of the items were excluded in analyzing the responses through PCA. The exclusion was based on low correlations between them and their category mean. On the remaining of 24 items, the discriminant analysis was conducted by categorizing them into groups of high and low scores based on the total score of other items. Accordingly, 11 items were removed; with an insignificant difference between the high score and low score groups as recommended by DeVellis (2016). During this process, none of the items were deleted until the consensus was reached between the researchers and 3 experts. Other than these, discussions were also done on the remaining 13 items with the experts. The items which were confusing and found redundant were removed. Resultantly, the final questionnaire of ER had 11 items only. These 11 items were transformed in the form of a questionnaire for data collection and further analyses in study 2.

\section{Study 2}

Since the ES behavior is pervasive in organizations, the self-report survey-based research was selected as the methodological approach in the second phase. The self-report method was chosen mainly because of the implicit nature of ES. Lack of action in ER, intentions, and ES makes it difficult for the observers to detect behavior, therefore the selfreport method is a recommended method in such scenarios (Wang et al., 2020; Wang \& Hsieh, 2013).

\section{Sampling Design}

The purposive sampling design was used. It served our specific purpose which was the selection of a respondent only if s/he answered the following questions positively 1) I have been working in the same organization from at least the last two years, 2) There are no major changes in the communication channels of my organization and 3) I have been with the same supervisor/line manager for at least last two years.

Data was collected in 3-time lags. Time lag research is a recommended way in research where intentions have been used as a predictor of a behavior (Fishbein \& Ajzen, 2011). Further, all the items are self-reported which could lead to common method bias; therefore, we adopted a time-lagged research design to mitigate common method bias Podsakoff et al., (2003).

In the first lag data for ER was collected, after the gap of 2 weeks the data for a mediator, intentions-to-remain-silent was collected. Finally, in the third lag data of ES was collected. The respondents were briefed about the research before the start of the data collection process.

\section{Data Collection Technique}

700 questionnaires were distributed among the employees working in the service sector. 253 valid questionnaires were received back (RR 36.7\%) which represents an adequate sample as determined through the G* Power application. It was used to run the power analysis as per the recommendations of Faul, Erfelder, Bucnhner, and Lang (2007). Keeping in view the research model, the sample size chosen for this research $(n=253)$, was larger than the one proposed by $\mathrm{G}^{*}$ Power 3.0, with the statistical sig. $(\alpha)$ level $5 \%$, and the required level of power of $80 \%$ (Hair et al., 1998), and the effect size of 15 (Cohen, 1988).

Demographic analysis revealed that $18.5 \%$ of the respondents were female. The female respondents were less mainly because of the overall $17.71 \%$ female workforce of the country within the age range of 21-65.

\section{Measures}

The scale for ER developed as the result of study 1, was used. Accordingly, its validity and reliability analysis such as face validity, content validity, reliability, item reliability, convergent validity, discriminant validity, nomological validity, and analysis was performed. The scale of intentions to remain silent was adapted based on the recommendations by Ajzen (2006). One of the items from the scale was, "In my organization, it is likely that I will remain silent on the topic of concern in the two weeks".

The measures of ER and intentions to remain silent asked participants to rate each scale item using the Likert scale (five points) with $5=$ strongly agree and $1=$ strongly disagree.

The scale of ES was adapted from Vakola and Bouradas (2005). One of the sample items from the scale was, "How often do you express your disagreements to your managers concerning your company's issues? The respondents evaluated the statements/indicators given in Table 2 .

Table 2: Factor Loading (bolded) and cross-loadings

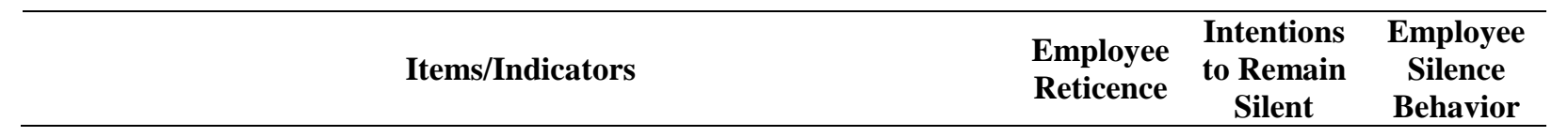




\begin{tabular}{|c|c|c|c|}
\hline ER1: In organizations, it is better to stay quiet than to give suggestions. & 0.7120 & & \\
\hline ER2: Remaining silent in organizations is beneficial. & 0.6841 & & \\
\hline ER3: In organizations, being silent is being wise. & 0.7610 & & \\
\hline $\begin{array}{l}\text { ER4: The job assignment which may lead to a conflict is delayed by me to } \\
\text { the last hour. }\end{array}$ & 0.7728 & & \\
\hline ER5: I like the people who prefer to remain silent over raising concerns. & 0.7315 & & \\
\hline ER6: In organizations, conflicts lead to better solutions. & 0.7644 & & \\
\hline $\begin{array}{l}\text { ER7: I wait for others to raise concerns about a common problem rather } \\
\text { than raising it by myself. }\end{array}$ & 0.8615 & & \\
\hline ER8: I prefer to leave things on fate than to raise voice about them. & 0.8470 & & \\
\hline ER9: I like the people who prefer to remain silent over giving suggestions. & 0.7426 & & \\
\hline $\begin{array}{l}\text { ITR 1: In my organization, it is likely that I will remain silent on an } \\
\text { important matter in the coming week }(\mathrm{s}) \text {. }\end{array}$ & & 0.7713 & \\
\hline $\begin{array}{l}\text { ITRS2: In my organization, most likely, I will hold a suggestion in the } \\
\text { coming week(s). }\end{array}$ & & 0.8458 & \\
\hline $\begin{array}{l}\text { ITRS3: In my organization, I plan to remain silent in the coming week(s) } \\
\text { even if I have something valuable to contribute. }\end{array}$ & & 0.8544 & \\
\hline $\begin{array}{l}\text { ITRS4: In my organization, I intend to remain silent in the coming week(s) } \\
\text { even if I am asked for suggestions. }\end{array}$ & & 0.8211 & \\
\hline $\begin{array}{l}\text { ES1: How often do you express your disagreements to your managers } \\
\text { concerning your department's issues? }\end{array}$ & & & 0.7499 \\
\hline $\begin{array}{l}\text { ES2: How often do you express your disagreements to your managers } \\
\text { concerning your company's issues? }\end{array}$ & & & 0.7007 \\
\hline $\begin{array}{l}\text { ES3: How easily do you express your disagreements to your managers } \\
\text { concerning company issues? }\end{array}$ & & & 0.7516 \\
\hline $\begin{array}{l}\text { ES5: How often do you express your disagreements to your managers } \\
\text { concerning your job? }\end{array}$ & & & 0.8195 \\
\hline $\begin{array}{l}\text { ES6: How easily do you express your disagreements to your managers } \\
\text { concerning your department's issues? }\end{array}$ & & & 0.8009 \\
\hline $\begin{array}{l}\text { ES7: How often do you express your disagreements to your managers } \\
\text { concerning issues related to job satisfaction such as salary, working } \\
\text { conditions etc }\end{array}$ & & & 0.7050 \\
\hline $\begin{array}{l}\text { ES8: How easily do you express your disagreements to your managers } \\
\text { concerning your job? }\end{array}$ & & & 0.7650 \\
\hline
\end{tabular}

The content validation step was performed with 6 academicians in the area of human resource management and 4 managers. The face validation step was performed with 4 Ph.D. scholars and 3 consultants. As a result, the changes were incorporated, and 2 redundant items were deleted. The final scale of ER now contained only 9 items.

Table 2 presents the final items/indicators with their respective constructs. Each item/indicator is a statement showing the manifestation of ER. Each scales' internal consistency, showing strong adhesion to the construct, was checked through Cronbach's alpha coefficient. The multivariate statistical approach was used to analyze the data statistically by using structural equation modeling (SEM). PLS-SEM is recommended by researchers over CB-SEM (Astrachan et al., 2014; Hair Jr et al., 2017; Sarstedt et al., 2014), therefore PLS-SEM was preferred over CB-SEB for this research. To test the normality assumption, Skewness and Kurtosis tests were used as per the recommendation of Hair et al., (2003) using SPSS 20.0. The scales were found within the normality range.

The quantitative analysis was done by bootstrapping directly in SmartPLS 2 with re samplings as recommended by Tenenhaus, Vinzi, Chatelin, and Lauro, (2005). The results of Cronbach's alpha and composite reliability are given in Table 3.

Table 3: Assessment of the measurement model; CR, Alpha, and AVE

\begin{tabular}{cccc}
\hline $\begin{array}{c}\text { Variable } \\
\text { construct }\end{array}$ & $\begin{array}{c}\text { The composite reliability (internal } \\
\text { consistency reliability) }\end{array}$ & $\begin{array}{c}\text { Cronbach's } \\
\text { Alpha }\end{array}$ & $\begin{array}{c}\text { The average variance } \\
\text { extracted/explained }\end{array}$ \\
\hline ER & 0.9270 & 0.9110 & 0.5865 \\
\hline ITRS & 0.8940 & 0.8414 & 0.6787 \\
\hline ESB & 0.9037 & 0.8774 & 0.5413 \\
\hline
\end{tabular}

All the values of composite reliabilities and the values of internal consistencies range from 0.870 to 0.93 , which are greater than the minimum recommended value of 0.70 (Hair et al., 2003; Nunnally \& Bernstein, 1994), thus confirming internal consistency. 
For item/indicator reliability, recommendation by Hair et al., (2003) was followed according to which the item loadings should exceed the minimum value 0.4 for items/indicators reliability. The items/indicators' reliability results are presented in Table 3, showing that all items loaded on their respective construct with a value ranging from 0.65 to 0.90 . The table also indicates that the items loaded highly on their constructs, in line with the recommendations by Howard (2016).

The convergent validity of each construct was evaluated by average variance extracted (AVE) as recommended by Hair et al., (2003). According to them the value of AVE should be at least 0.50 to ascertain convergent validity. The values of AVE in this research are shown in Table 3. It can be seen that the values of the AVE are greater than 0.50 for all the constructs, showing convergent validity of each construct. To complement the AVE findings, convergent validity was also tested by the values of cross-loadings of items on their latent constructs, which was found to be significant ( $\mathrm{p}<$ 0.05). T-statistics results were also indicative of the same as shown in the loadings of outer model loadings in the output of PLS-graph. These values ranged from a low of 16 to a high value of 36 . The constructs' convergent validity is confirmed from items' loadings and cross-loadings presented in Table 2. Further significant T-statistics for each individual item loading confirm the convergent validity of these indicators as representing distinct latent constructs. Therefore, the validation criteria for internal consistency and the convergent validity were found to be satisfactory, confirming our proposed construct of ER.

According to Fronell and Larcker (1981), the discriminant validity is confirmed if the square root of the AVE is higher than the correlation among all the latent constructs/variables. It is evident from Table 4, as the AVE square roots, show in diagonal, are greater than other elements in respective columns and rows.

Table 4: Discriminant validity (intercorrelations) of variable constructs

\begin{tabular}{lllll}
\hline \multicolumn{2}{l}{ Variables } & 1 & 2 & 3 \\
\hline 1 & ER & $\mathbf{0 . 7 6 6 1}$ & & \\
\hline 2 & ITRS & 0.7153 & $\mathbf{0 . 8 2 3 8}$ & \\
\hline 3 & ESB & 0.5331 & 0.7130 & $\mathbf{0 . 7 3 5 7}$ \\
\hline
\end{tabular}

Figure. 2 shows the analysis results (structural model). The beta values of all path coefficients are shown which are statistically significant (at $\mathrm{p}<0.05$ ). ER had a positive influence (beta $=0.715, \mathrm{p}<0.001$ ) on intentions to remain silent. Intentions to remain silent had a positive influence (beta $=0.679, \mathrm{p}<0.001$ ) on ES. The model explains $51.2 \%$ of the variance in intentions to remain silent and $50.9 \%$ of the variance in ES. Table 5 presents the hypotheses, outcomes, and conclusions as to the result of the analysis.

Table 5: Hypotheses Conclusions

\begin{tabular}{|c|c|c|}
\hline Hypotheses & Findings & Conclusion \\
\hline H1: Employee Reticence is positively related to Intention to Remain Silent. & $\begin{array}{c}\text { Yes: }(\text { beta }=0.715, \mathrm{p}< \\
0.05)\end{array}$ & Supported \\
\hline H2: Intentions to Remain Silent is positively related to Employee Silence. & $\begin{array}{c}\text { Yes: }(\text { beta }=0.679, \mathrm{p}< \\
0.05)\end{array}$ & Supported \\
\hline $\begin{array}{l}\text { H3: Intentions to Remain Silent fully mediates the relationship between Employee } \\
\text { Reticence and Employee Silence. }\end{array}$ & $\begin{array}{c}\text { Yes: Direct path } \\
\text { insignificant }\end{array}$ & Supported \\
\hline
\end{tabular}

\section{DISCUSSION}

In this research, the employee reticence phenomenon was proposed, and its scale was developed and validated. ER has been defined as an attitude towards ES. During the qualitative phase, in-depth semi-structured interviews confirmed the presence of such attitudes in the employees. As the result of the qualitative phase of the study, three dimensions of ES that is cognitive employee reticence, affective ER, and behavioral ES were also discovered. In the quantitative phase, two studies were done. In the first study, the developed scale was finalized by performing PCA and expert opinion. In the second study using internal consistency, content validity, face validity, discriminant validity, nomological validity tests, and analysis of the research model were performed.

The PLS-SEM analysis of the study showed acceptance of the hypotheses, thereby suggesting a significant relationship between the ER and ES mediated by intentions to remain silent. In other words, the greater the ER the greater would be the employee's intentions to remain silent, consequently leading to the ES. This is in line with the theory of reasoned action (Fishbein \& Ajzen, 2011), the TPB (Ajzen, 2006), functional attitude theory (Katz, 1964), and attitude-behavior consistency principle (Haddock \& Maio, 2007). Thus, if an employee is high at ER the employee will intend to remain silent.

Finally, the intentions to remain silent (ITRS) was found to have a significant positive effect on ES. This is in line with the theory of reasoned action (Ajzen \& Fishbein, 2005) and TPB (Ajzen, 1985) and consistent with findings of multiple research based on these theories. That is to say, if an employee has intentions to remain silent, the employee is likely to exhibit the behavior of silence. Therefore, in an organization, if an employee is asked for the input, the employee with 
intentions to remain silent will remain silent even if the employee has something important to contribute. Further, it was found that intentions to remain silent fully mediate the relationship between ER and ES. As shown in figure 2, the direct path from ER to ES is insignificant depicting full mediation of intentions. This is in line with the theory of reasoned action (Fishbein \& Ajzen, 2011).

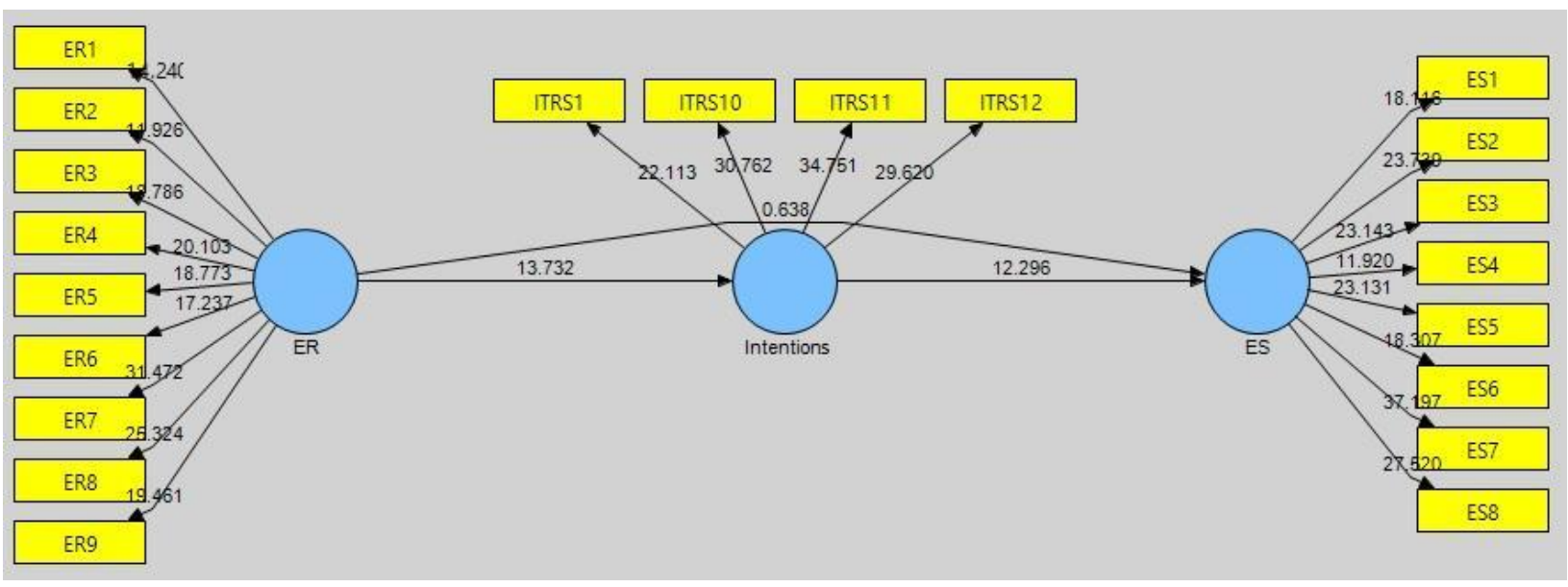

Figure 2: Structural Model Results

In this research, ER has been introduced, and its scale has been developed, validated, and tested. This is an addition to the silence literature by presenting a new attitudinal variable that is ER, which can be used in studies related to ES, respondent's bias, attitudinal and behavioral modification studies, etc. It can be used to develop and test new theories related to ES, personality, knowledge sharing, teamwork, stress, anxiety, employee health problems, harassment, and bullying.

The introduction of the intention to remain silent as a mediator between ER and ES will pave the way to find answers to why employees choose to remain silent despite being the witness and victim of bullying, harassment, and alike behaviors in organizations.

In organizations, successful management requires continuous feedback and input from lessons learned, however, ES impedes improvements and corrections (Dedahanov et al., 2016). It is a matter of prime importance to mitigate ES. Attitudinal updating seems to be the easiest way of doing it. ER scale can be used for different types of research design including pre-test, post-test research design for attitudinal updating of employees. Further, change management programs, innovative and creative jobs require continuous knowledge sharing and feedback. The recruiters and managers can use ER scale for the initial screening of the candidates for such types of jobs.

\section{CONCLUSION}

In this research, the phenomenon of employee reticence has been proposed and its scale has been developed and tested. The scale development of ER builds upon and extends previous theoretical and empirical work on attitudes and behaviors by bringing in new perspectives in the existing body of knowledge on ES. Although previous research on ES has focused mainly on organizational factors, this research on employee attitude towards silence has furthered our understanding of why employees choose to remain silent. Conceivably, the recruiters, OB-interventionists, and researchers are greatly to benefit from this research because existing measures do not assess employee attitude towards silence. Keeping in view the abundance of evidence on the negative role of ES in cases such as the Challenger space shuttle disaster and Enron (Lalich et al., 2018), there is little doubt that organizations of all types could benefit from better understanding the antecedents of ES such as ER.

\section{LIMITATION AND FUTURE RECOMMENDATIONS}

Although this research has advanced our understanding of attitudes, it is just the beginning of building the foundations of ES attitude. This research has not only confirmed the presence of such an attitude but also developed and validated its scale.

The limitations of the scale of the ER can be removed by further delineating it with the dimensions of attitude that are cognitive, affective, and behavioral dimensions. Moreover, with the availability of ER scale, further research can be guided to predict its antecedents and consequences.

Based on the recommendation of TPB, other variables such as organizational silence, manager's attitude can also be included as IV to represent subjective norms, and communication opportunities can be included as IV to represent perceived behavioral control. Personality and gender may be used as moderators. In addition, organizational and teamlevel attitudes of silence can be explored. Further, the same research may be replicated in non-service sectors and projects, where ER and ES can have devastating effects on project success. 
Finally, the readers in general, and the organizational behaviorists, in particular, will greatly benefit from this concept and scale. Its scale is a useful tool, largely for organizational behaviorists for change intervention programs and recruiters for ensuring PO fit. It will also be of use to researchers for further exploration and using it as in organizational research including but not limited to ES, knowledge management, and stress. Psychologists can take the lead from the concept of ER to develop similar constructs for their field for analyzing their patients of stress etc. from this perspective.

\section{ACKNOWLEDGEMENT}

We acknowledge the continuous support of Mr. Khusro Pervaiz Khan, Head of Campus, SZABIST Islamabad has played pivotal role in providing the motivation in his own way to complete the work. The support of Dr. Arshad Hassan, Dean, FOMSS CUST. We are equally thankful to the Head of Department of FOMSS, CUST for his guidance. We acknowledge the contribution of Dr. Khansa Zaman, Assistant Professor, and Dr. Shazia Akhtar, Associate Professor, in guiding our research work in addressing the technical and other issues. Further, a special note of thanks to Engr. Muhammad Khalid, Director GSO, CUST for continuously pushing towards the completion of the research paper for meeting the degree requirements. It is to confirm that there was no financial support awarded for this research.

Last but not the least are the family members, without their continuous support, this would have not been possible.

\section{AUTHORS CONTRIBUTION}

Mr. Ahmed Ali Qureshi, contributed to the research work from literature review, identifying the gap and problem, and shaping up the research work, data collection, and concluding the same. Dr. Sayyed Muhammad Mehdi Raza Naqvi helped in finalizing the research problem, research methodology, data collection and provided guidance on every stage of the research work. Mr. Ahmed Ali Qureshi is thankful to Dr. Sayyed M. Mehdi Raza Naqvi for his continuous guidance and support towards the completion of the research work.

\section{REFERENCES}

1. Abd El-Fattah Mohamed Aly, N., El-Shanawany, S. M., \& Ghanem, M. (2021). Workplace silence behavior and its consequences on nurses: A new Egyptian validation scale of nursing motives. Clinical Ethics. https://doi.org/10.1177/1477750921994284

2. Ajzen, I. (1985). From intentions to actions: A theory of planned behavior. Springer. https://doi.org/10.1007/978-3-642-69746-3_2

3. Ajzen, I. (2006). Constructing a TPB questionnaire: Conceptual and methodological considerations. http://chuang.epage.au.edu.tw/ezfiles/168/1168/attach/20/pta_41176_7688352 57138.pdf

4. Ajzen, I., \& Fishbein, M. (2005). The influence of attitudes on behavior. The Handbook of Attitudes, 173(221), 31.

5. Armitage, C. J., \& Christian, J. (2003). From attitudes to behaviour: Basic and applied research on the theory of planned behaviour. Current Psychology, 22(3), 187-195. https://doi.org/10.1007/s12144-003-1015-5

6. Astrachan, C. B., Patel, V. K., \& Wanzenried, G. (2014). A comparative study of CB-SEM and PLS-SEM for theory development in family firm research. Journal of Family Business Strategy, 5(1), 116-128. https://doi.org/10.1016/j.jfbs.2013.12.002

7. Benevene, P. (2020). Managing silence in workplaces. Journal of Workplace Learning, 32(1), 94-95. https://doi.org/10.1108/JWL-02-2020-157

8. Boateng, G. O., Neilands, T. B., Frongillo, E. A., Melgar-Quiñonez, H. R., \& Young, S. L. (2018). Best Practices for Developing and Validating Scales for Health, Social, and Behavioral Research: A Primer. Frontiers in Public Health, 6. https://doi.org/10.3389/fpubh.2018.00149

9. Byrne, D. (1961). Interpersonal attraction and attitude similarity. The Journal of Abnormal and Social Psychology, 62(3), 713. https://doi.org/10.1037/h0044721

10. Charmaz, K. (2006). Constructing grounded theory: A practical guide through qualitative analysis. Sage.

11. Chen, G., Ployhart, R. E., Thomas, H. C., Anderson, N., \& Bliese, P. D. (2011). The power of momentum: A new model of dynamic relationships between job satisfaction change and turnover intentions. Academy of Management Journal, 54(1), 159-181. https://doi.org/10.5465/amj.2011.59215089

12. Cohen, J. (1988). Statistical Power Analysis for the Behavioral Sciences (2 edition). Routledge.

13. Dedahanov, A. T., Lee, D. H., \& Rhee, J. (2016). Silence as a mediator between organizational factors and stress. Journal of Managerial Psychology, 31(8), 1251-1264. https://doi.org/10.1108/JMP-09-2014-0265

14. DeVellis, R. F. (2016). Scale development: Theory and applications (Vol. 26). Sage publications.

15. Dyne, L. V., Ang, S., \& Botero, I. C. (2003). Conceptualizing Employee Silence and Employee Voice as Multidimensional Constructs*. Journal of Management Studies, 40(6), 1359-1392. https://doi.org/10.1111/1467-6486.00384

16. Eagly, A. H., \& Chaiken, S. (1993). Psychology of Attitudes (1 edition). Wadsworth Publishing.

17. Eagly, A. H., \& Chaiken, S. (2005). Attitude Research in the 21st Century: The Current State of Knowledge.

18. Faul, F., Erdfelder, E., Lang, A.-G., \& Buchner, A. (2007). G*Power 3: A flexible statistical power analysis program for the social, behavioral, and biomedical sciences. Behavior Research Methods, 39(2), 175-191. https://doi.org/10.3758/BF03193146 
19. Fazio, R. H. (1990). Multiple processes by which attitudes guide behavior: The MODE model as an integrative framework. In Advances in experimental social psychology (Vol. 23, pp. 75-109). Elsevier. https://doi.org/10.1016/S0065-2601(08)60318-4

20. Fishbein, M., \& Ajzen, I. (2011). Predicting and Changing Behavior: The Reasoned Action Approach. Taylor \& Francis. https://doi.org/10.4324/9780203838020

21. Fornell, C., \& Larcker, D. F. (1981). Evaluating Structural Equation Models with Unobservable Variables and Measurement Error. Journal of Marketing Research, 18(1), 39-50. https://doi.org/10.2307/3151312

22. Götz, M., Knoll, M., Adriasola Barroilhet, A., Arenas, A., Barrett, S., Bollmann, G., Carter, M., Chui, S., Di Marco, D., Elsey, V., Gatti, P., Ghislieri, C., Hofmans, J., Jønsson, T. F., Lundsgaard Ottsen, C., Pickett, J. L., Retowski, S., Silva, S. A., Šimunić, A., ... Zacher, H. (2019). Remaining silent in eleven languages: Validating scales for employee silence motives across fifteen countries. EAWOP 2019 Abstract Book, 462.

23. Haddock, G., \& Maio, G. R. (2007). Attitude-Behavior Consistency. In Encyclopedia of Social Psychology (pp. 60-61). SAGE Publications, Inc. https://doi.org/10.4135/9781412956253

24. Hair, J., Hult, G. T. M., Ringle, C. M., \& Sarstedt, M. (2013). A Primer on Partial Least Squares Structural Equation Modeling (1 edition). SAGE Publications, Inc. https://doi.org/10.1016/j.lrp.2013.01.001

25. Hair Jr, J. F., Matthews, L. M., Matthews, R. L., \& Sarstedt, M. (2017). PLS-SEM or CB-SEM: Updated guidelines on which method to use. International Journal of Multivariate Data Analysis, 1(2), 107-123. https://doi.org/10.1504/IJMDA.2017.087624

26. Howard, M. C. (2016). A Review of Exploratory Factor Analysis Decisions and Overview of Current Practices: What We Are Doing and How Can We Improve? International Journal of Human-Computer Interaction, 32(1), 51-62. https://doi.org/10.1080/10447318.2015.1087664

27. Howard, R., Restrepo, L., \& Chang, C.-Y. (2017). Addressing individual perceptions: An application of the unified theory of acceptance and use of technology to building information modelling. International Journal of Project Management, 35(2), 107-120. https://doi.org/10.1016/j.ijproman.2016.10.012

28. Jones, W. H., \& Russell, D. (1982). The Social Reticence Scale: An Objective Instrument to Measure Shyness. Journal of Personality Assessment, 46(6), 629-631. https://doi.org/10.1207/s15327752jpa4606_12

29. Katz, D. (1964). The motivational basis of organizational behavior. Behavioral Science, 9(2), $131-146$. https://doi.org/10.1002/bs.3830090206

30. Knoll, M., \& Redman, T. (2016). Does the Presence of Voice Imply the Absence of Silence? The Necessity to Consider Employees' Affective Attachment and Job Engagement. Human Resource Management, 55(5), 829844. https://doi.org/10.1002/hrm.21744

31. Knoll, M., \& van Dick, R. (2013). Do I hear the whistle...? A first attempt to measure four forms of employee silence and their correlates. Journal of Business Ethics, 113(2), 349-362. https://doi.org/10.1007/s10551-0121308-4

32. Kruglanski, A. W., \& Stroebe, W. (2005). The influence of beliefs and goals on attitudes: Issues of structure, function, and dynamics. The Handbook of Attitudes, 323-368.

33. Lalich, J., McLaren, K., Lalich, J., McLaren, K., Lalich, J., McLaren, K., Lalich, J., McLaren, K., Lalich, J., \& McLaren, K. (2018). Charismatic Leadership and Corporate Cultism at Enron: The Elimination of Dissent, The Promotion of Conformity and Organizational Collapse. In Escaping Utopia: Growing Up in a Cult, Getting Outs, and Starting Over (Vol. 7, pp. 17-21). McGraw Hill New York. https://doi.org/10.4324/9781315295091

34. Lam, L. W., \& Xu, A. J. (2019). Power Imbalance and Employee Silence: The Role of Abusive Leadership, Power Distance Orientation, and Perceived Organisational Politics. Applied Psychology, 68(3), 513-546. https://doi.org/10.1111/apps. 12170

35. Morrison, E. W. (2011). Employee voice behavior: Integration and directions for future research. The Academy of Management Annals, 5(1), 373-412. https://doi.org/10.5465/19416520.2011.574506

36. Morrison, E. W. (2014). Employee Voice and Silence. Annual Review of Organizational Psychology and Organizational Behavior, 1(1), 173-197. https://doi.org/10.1146/annurev-orgpsych-031413-091328

37. Nunnally, J. C., \& Bernstein, I. H. (1994). Psychometric Theory (3rd edition). McGraw-Hill.

38. Organ, D. W. (1988). Organizational citizenship behavior: The good soldier syndrome. Lexington Books/DC Heath and Com.

39. Orpen, C. (1984). Attitude Similarity, Attraction, and Decision-Making in the Employment Interview. The Journal of Psychology, 117(1), 111-120. https://doi.org/10.1080/00223980.1984.9923666

40. Podsakoff, P. M., MacKenzie, S. B., Lee, J.-Y., \& Podsakoff, N. P. (2003). Common method biases in behavioral research: A critical review of the literature and recommended remedies. Journal of Applied Psychology, 88(5), 879. https://doi.org/10.1037/0021-9010.88.5.879

41. Priola, V., Lasio, D., Simone, S. D., \& Serri, F. (2014). The Sound of Silence. Lesbian, Gay, Bisexual and Transgender Discrimination in 'Inclusive Organizations.' British Journal of Management, 25(3), 488-502. https://doi.org/10.1111/1467-8551.12043

42. Sarstedt, M., F. Hair Jr, J., Hopkins, L., \& G. Kuppelwieser, V. (2014). Partial least squares structural equation modeling (PLS-SEM): An emerging tool in business research. European Business Review, 26(2), 106-121. https://doi.org/10.1108/EBR-10-2013-0128 
43. Shukla, A., Srinivasan, R., \& Chaurasia, S. (2013). Impact of Work Related Attitudes on Turnover Intention. Indian Journal of Industrial Relations, 49(1), 111-122.

44. Tangirala, S., \& Ramanujam, R. (2012). Ask and you shall hear (but not always): Examining the relationship between manager consultation and employee voice. Personnel Psychology, 65(2), 251-282. https://doi.org/10.1111/j.1744-6570.2012.01248.x

45. Tenenhaus, M., Vinzi, V. E., Chatelin, Y.-M., \& Lauro, C. (2005). PLS path modeling. Computational Statistics \& Data Analysis, 48(1), 159-205. https://doi.org/10.1016/j.csda.2004.03.005

46. Thams, Y., Bendell, B. L., \& Terjesen, S. (2018). Explaining women's presence on corporate boards: The institutionalization of progressive gender-related policies. Journal of Business Research, 86, 130-140. https://doi.org/10.1016/j.jbusres.2018.01.043

47. Vakola, M., \& Bouradas, D. (2005). Antecedents and consequences of organisational silence: An empirical investigation. Employee Relations, 27(5), 441-458. https://doi.org/10.1108/01425450510611997

48. Valentine, S., Godkin, L., Fleischman, G. M., \& Kidwell, R. (2011). Corporate Ethical Values, Group Creativity, Job Satisfaction and Turnover Intention: The Impact of Work Context on Work Response. Journal of Business Ethics, 98(3), 353-372. https://doi.org/10.1007/s10551-010-0554-6

49. Wang, C.-C., Hsieh, H.-H., \& Wang, Y.-D. (2020). Abusive supervision and employee engagement and satisfaction: The mediating role of employee silence. Personnel Review, 48(9), 1845 - 1858. https://doi.org/10.1108/PR-04-2019-0147

50. Wang, Y.-D., \& Hsieh, H.-H. (2013). Organizational ethical climate perceived organizational support, and employee silence: A cross-level investigation. Human Relations, 66(6), 783-802. https://doi.org/10.117 7/0018726712460706 